\title{
HOW EFFECTIVE IS REDISTRIBUTION UNDER THE SOCIAL SECURITY BENEFIT FORMULA?
}

\author{
Alan L. Gustman \\ Thomas L. Steinmeier \\ Working Paper 7597 \\ http://www.nber.org/papers/w7597 \\ NATIONAL BUREAU OF ECONOMIC RESEARCH \\ 1050 Massachusetts Avenue \\ Cambridge, MA 02138 \\ March 2000
}

This paper is funded by a grant from the Social Security Administration to the Michigan Retirement Research Center, with subcontracts to the National Bureau of Economic Research and Dartmouth College. It is part of the NBER programs in Labor Studies and Aging. Any opinions expressed are those of the authors, and not of the Social Security Administration, the Michigan Retirement Research Center, or the National Bureau of Economic Research. We would like to thank Olivia Mitchell, Jon Skinner and David Weir for their helpful comments, and Doug Staiger and Steve Venti for useful discussions.

(C) 2000 by Alan L. Gustman and Thomas L. Steinmeier. All rights reserved. Short sections of text, not to exceed two paragraphs, may be quoted without explicit permission provided that full credit, including (C) notice, is given to the source. 
How Effective is Redistribution Under the Social Security Benefit Formula?

Alan L. Gustman and Thomas L. Steinmeier

NBER Working Paper No. 7597

March 2000

JEL No. H55, J14, J26, D31

\begin{abstract}
This paper uses earnings histories obtained from the Social Security Administration and linked to the survey responses for participants in the Health and Retirement Study to investigate redistribution under the current social security benefit formula. We find that as advertised, at the level of the individual respondent, the benefit formula is progressive. When individuals are arrayed by indexed lifetime earnings, own benefits are significantly redistributed from those with high lifetime earnings to those with low lifetime earnings. However, much of this apparent redistribution is from men to women, and when examined at the level of the family, from primary to secondary earners. When families are arrayed according the total lifetime earnings, and spouse and survivor benefits are taken into account, the extent of redistribution from families with high lifetime earnings to families with low lifetime earnings is roughly halved. Much of the remaining redistribution is from families where both spouses spend much of their potential work lives in the labor market, to families where a spouse, often with high earnings potential, chooses to spend a significant number of years outside of the labor force. When families are arrayed by their earnings potential, that is earnings during years when both spouses are engaged in substantial work, there is very little redistribution from families with high to low earnings capacity.

Accordingly, at least for families on the verge of retirement today, introducing a simple system of privatized or other individual accounts, i.e., a system that ignored issues of redistribution, would have no major effect on the distribution of social security benefits net of taxes among families with different earnings capacities. Moreover, although privatized or other individual accounts would reduce redistribution from two earner to one earner families, the extent of that redistribution is greatly exaggerated when one compares benefits among individuals arrayed according to lifetime earnings.
\end{abstract}

Alan L. Gustman

Department of Economics

Dartmouth College

Hanover, N.H. 03755

and NBER

alan.l.gustman@dartmouth.edu
Thomas L. Steinmeier

Department of Economics

Texas Tech University

Lubbock, TX 79409

Thomas.Steinmeier@TTU.edu 


\section{Introduction.}

This paper examines how a system with a progressive formula specified according to individual earnings, supplemented by a policy designed to redistribute benefits from dual earner toward single earner families, affects the distribution of benefits among families with different lifetime earnings or earning capacities. The conventional wisdom is that the social security benefit formula is highly redistributive, favoring low over high earners. It certainly is true that the structure of the benefit formula is highly progressive, replacing, up to maximum covered earnings, a much higher share of earnings for individuals with low than high earnings. The focus on the individual may be misplaced, however. From a public policy perspective, the proper accounting unit for evaluating redistribution is the family.

The distribution of family earnings will differ from the distribution of individual earnings. The relation of the earnings distributions for individuals and for families will depend on the correlation of the wage and labor supply for each spouse and between spouses. If wives have lower wages than husbands, then we can expect less redistribution among families than among individuals, since some of the redistribution at the individual level will be from husbands with greater lifetime earnings to their wives with lower lifetime earnings.

A second factor which mitigates the degree of redistribution is that in addition to benefits based on own earnings, social security often pays additional spouse or survivor benefits to low earning spouses. The amount of these benefits depend on the earnings of the spouse, and are greater the greater the difference between the lifetime earnings of the two spouses. ${ }^{1}$ The evidence suggests spouse

\footnotetext{
${ }^{1}$ Spouse and survivor benefits almost always accrue to the woman in the household. For example, in 1998, there were 2.5 million women and 24,000 men who were dual beneficiaries receiving
} 
and survivor benefits are larger in families with high earnings. If husbands with high earnings are married to spouses with considerably lower lifetime earnings, spouse and survivor benefits will be more important in high income families. This, in turn, implies that social security will foster less redistribution among households than among individuals (Steuerle and Bakija, 1994).

Low lifetime earnings may arise because individuals have low wage rates, or because they work few hours or years. Families with similar earnings capacities can supply different amounts of labor over their lifetimes, and the current policy effectively subsidizes families with a spouse who, although working at least ten years to qualify for benefits, remains home for many years rather than working in the market. $^{2}$ To determine the extent to which families that supply less time to the labor market benefit disproportionately under the current system, we will examine redistribution among families when they are arrayed by their earnings capacities as well as by their realized lifetime earnings.

This paper documents the sources and characteristics of redistribution from these various features of the social security benefit formula, and from the relation between individual and family earnings. The next section discusses the workings of the social security benefit calculation in more detail, and Section III discusses the data used in the study. The principal data source is social security earnings records in the Health and Retirement Study (HRS), and this is supplemented by the spouse benefits (Social Security Administration, 1999, Table 5.G3). Similarly, 4.8 million women and 36,000 men received nondisabled widows' or widowers' benefits in 1998 (Social Security Administration, Table 5.F8).

${ }^{2}$ In Gustman and Steinmeier (2000), we find that the social security benefit formula fosters redistribution to immigrants, and provides the highest returns to immigrant families who have been in the U.S. for ten years and who have high yearly earnings. Something similar is going on here among those who qualify for social security benefits, allowing families with a member who has been in the labor force for relatively few years to enjoy a higher benefit-tax ratio. 
respondents' reports of their work histories. Section IV considers years of work and earnings in those years for respondents falling into different lifetime earnings categories. The lifetime earnings used is Average Indexed Monthly Earnings (AIME), the same measure as is used by the Social Security Administration. Especially in the low AIME categories, low lifetime earnings can arise either because the respondent worked relatively few years or because annual earnings were low. The next section calculates redistribution measures for individual and for families, and groups the results according to both individual lifetime earnings and family lifetime earnings. Section VI considers what the redistribution looks like when we group families according to a measure of the potential earnings that the families could have earned if both spouses had worked most or all of their adult years. ${ }^{3}$

The calculations we will make are directly relevant to the debate about the effects of privatizing some or all of the Social Security System. It is often argued that privatization would undermine the redistribution fostered by the progressive social security benefit formula.

For example, in commenting on our analysis of outcomes under a particular proposal for a voluntary privatization system (Gustman and Steinmeier, 1998), David Cutler (1998, p. 358) argues:

"We typically think that giving people choice is optimal since people can decide what is best for them. Thus the economic bias is to believe that, if people want to opt out of social security, they should be allowed to do so. In the context of social security privatization, however, this analysis is not right. Allowing people to opt out of social security to avoid adverse redistribution is not efficient; it just destroys what society was trying to accomplish. If rich people and two-worker families opt out of social security,

${ }^{3}$ Some lawmakers strongly advocate the payment of spouse and survivor benefits to encourage one parent to remain at home with young children. To equalize the treatment of one and two earner households under social security, other lawmakers have proposed various plans that would split the credit for earnings in any year evenly between both household members, while eliminating spouse and survivor benefits. 
for example, we will no longer be able to redistribute from rich to poor or from dual earners to single earners. One of the purposes of social security will have been defeated. This is a cost of privatization of which we must be aware."

Our analysis will determine just how much redistribution the current system fosters. This information is required by policy makers to decide whether they are still happy with the redistribution that is being fostered by a set of rules established many years ago, when the typical household had a single earner. The calculations will also provide a benchmark to help understand the effects of various reforms. Any large change in the system is going to require an accounting of winners and losers, which in turn depends on the extent of redistribution under the current system. In addition, a major determinant of whether, if given the choice, individuals would choose to participate in a system of privatized or other individual social security accounts over the current system, or to vote for a privatized system, is whether or not they benefit from redistribution under the current system.

There are a number of new and related papers on social security redistribution which use different data sets and focus on somewhat different calculations from those in our study. Liebman (1999), in a paper completed contemporaneously with our own, modifies data from the Survey of Income and Program Participation, using cohorts born from 1925 to 1929 and 1945 to 1949. As in our paper, Liebman has available matched earnings records from the Social Security Administration. He creates a simulation model and uses the model to analyze redistribution due to social security, and to project redistribution under the current social security rules and into the future, with life tables and tax and benefit values for 2075. Coronado, Fullerton and Glass (1999a and b) construct covered earnings histories from PSID data, and construct a simulation model which they use to analyze the effects on the 
distribution of benefits and taxes of various schemes to reform social security. ${ }^{4}$ One of their concerns is with earnings capacity, so they focus on benefit and tax distribution by total family potential lifetime income. While potential lifetime income is computed on the assumption that both spouses work full time throughout their potential work lives, benefits and taxes are computed from the earnings histories in the PSID data and projections are based on the actual work histories. Feldstein and Liebman (1999) use the data for the 1925 to 1929 birth cohort from SIPP, the same data as in Liebman (1999), to analyze redistribution under proposed privatization reforms.

\section{A Conceptual Framework.}

\section{A. How the Social Security Benefit Formula Works.}

For each individual, the Social Security Administration calculates a measure of lifetime earnings which is an average of the high 35 years of earnings, with zeros used if the individual has not worked 35 years. A progressive benefit formula is then applied so that those who have low computed lifetime earnings have a higher benefits, relative to earnings, than do those with high earnings. Specifically, the formula for 2000 specifies benefits that are 90 percent of the first $\$ 6,372$ of annual earnings, 32 percent of the next $\$ 32,052$, and 15 percent of remaining earnings. The earnings measure is typically expressed

${ }^{4}$ To be included in the sample, Coronado, Fullerton and Glass require that the respondent remain in the PSID sample for the entire period. Although the effects of attrition bias are not clear, this is a very selective sample since low earners and the divorced are more likely to be lost. In contrast, when social security earnings records are available for a representative sample as in the HRS, attrition over the period is not an issue. To be sure, selection bias in matching the social security records for survey respondents is an issue. However, studies to date do not show any important systematic relationship between observables and the availability of a matched social security record in the HRS (Gustman and Steinmeier, 1999; Haider and Solon, 1999; and Olson, forthcoming). 
as a monthly amount, the Average Indexed Monthly Earnings (AIME), and the benefit amount is called the Primary Insurance Amount (PIA). By applying a progressive benefit formula to each individual's own AIME, benefits are redistributed to those individuals with low covered earnings over their lifetimes.

Benefits to spouses and survivors affect the relationship between benefits and earnings, both at the level of the individual and at the level of the family. Spouses are entitled to roughly half of their partner's benefits, and survivors are entitled to an amount roughly equal to the benefits that would have been payable to the deceased spouse. ${ }^{5}$ Divorced individuals can collect benefits as though they were still married as long as the marriage lasted longer than 10 years. In all cases, an individual is paid first the benefit that he or she would collect on the basis of his or her own earnings record. If the spouse or survivor benefits would be more, the individual is considered a "dual beneficiary," and an additional payment is made to raise the benefits to the level of spouse or survivor benefits they are entitled to. ${ }^{6}$

As a result of these rules, only the high earner in a household generates spouse and survivor benefits for their spouse. In addition, the more a secondary earner makes, the less spouse and survivor benefits are worth to the family. Thus spouse and survivor benefits are of greatest value to one earner couples, which often are families where the earnings of the working spouse are relatively high. For such

${ }^{5}$ The exact payments to each spouse also depend on when the benefits are claimed. These rules are described in The Annual Statistical Supplement to the Social Security Bulletin.

${ }^{6}$ There are exceptions when a spouse was employed in a job not covered by social security, in particular as a state and local government worker who did not contribute to the system. There also are other exceptions governing the benefits of individuals who have pensions from uncovered employment. The Social Security System also provides benefits to the disabled and to surviving minor children. This paper is concerned with old age and survivors benefits, and does not address the issue of the distribution of disability or other benefits than retirement, spouse an survivor benefits. 
families, while the progressive benefit formula would appear to work to the advantage of a secondary earner, the availability of spouse and survivor benefits largely negates this advantage. Even if the secondary worker did not work, he or she would often collect nearly the same amount of benefits anyway as spouse or survivor benefits.

\section{B. Individual Versus Family Earnings.}

However benefits are calculated, whether they include only the basic benefit or spouse and survivor benefits, measures of redistribution will differ depending on whether they are calculated over individuals or over families. Thus it is worthwhile to briefly discuss how earnings in the family relate to earnings by individuals.

Lifetime income for each individual is the sum over the working life of the individual's wage rate in each year times the fraction of that year worked. Some of the individual earners are husbands and some are wives. Typically, the earnings of wives are lower than those of their husbands, because the wage rate is lower, because the fraction of each year worked is lower, and because the number of years worked are lower. As a result, redistribution fostered by the Social Security System, when measured among individuals, will to some extent involve redistribution from husbands with higher earnings to wives with lower earnings.

Thus when we ask how well social security redistributes benefits among families according to their incomes, and how the redistribution among families relates to the redistribution among individuals, it will be important to consider how individuals aggregate into family units. Lifetime family incomes are simply the sum of the lifetime individual incomes of the two spouses. As Smith (1979) carefully explains, the relationships between the distributions of individual and family earnings will depend on the 
correlation between the wage offers to husbands and their wives, which we expect to be positive as long as schooling is correlated between husbands and wives, and on the variation of labor supply with own and with spouse's earnings. If wives work less in households where husbands have high earnings, that will narrow the distribution of family earnings relative to the earnings distribution of individual earnings.

Our aim in the empirical section is to determine the extent of redistribution fostered by the current Social Security System on the basis of each individual's earnings, and then to see how the extent of redistribution changes when we instead look at redistribution on the basis of total family earnings and finally at redistribution on the basis of potential family earnings, which is what the family could earn if both partners worked full time.

\section{The Data.}

The Health and Retirement Study (HRS) is a longitudinal, nationally representative study of older Americans. The survey began in 1992 with an initial cohort of 12,652 individuals from 7,607 households, with at least one household member born from 1931 to 1941. Social security earnings histories were linked for 9472 respondents, or about 75 percent of the respondents to the survey. ${ }^{7}$ Of the respondents with linked earnings histories, there were 7370 who were born between 1931 and 1941, for whom the HRS is representative. In the HRS nomenclature, these respondents are said to be

${ }^{7}$ In wave 1,72 percent of respondents gave permission to link social security earnings histories to their interview record. That was raised to 80 percent as a result of additional attempts in waves 2 and 3 to obtain permissions. Records were actually linked for 95 percent of those who gave permissions. 
"age eligible." The remaining respondents are included in the survey because they were married to age eligible respondents, but by themselves they do not form a representative sample of those age groups.

There are a number of caveats we should mention at the outset of the empirical analysis. First, the HRS samples a cohort born from 1931 to1941. Members of that cohort exhibit higher levels of women's labor force participation than are found in cohorts born before them, but lower levels of participation than are found for cohorts born after 1941. Thus the redistribution fostered by the Social Security System will differ for the cohorts who follow the HRS.

The analysis uses the current benefit law and the tax schedules in place at the time wages were earned. The rules governing social security will certainly be subject to change as policy makers attempt to introduce financial balance into a system that is insolvent in the long run. But the HRS cohort is old enough that while its members may experience some reduction in social security benefits, the scope for such a reduction is narrowing as the cohort ages. For example, even if there were a compromise that raised the normal retirement age, as time passes, such a compromise is less and less likely to be applied to those born before 1941. Since most of the social security taxes levied on the HRS cohort have already been paid, payroll tax increases enacted in the future also will have limited effect on the members of this cohort. ${ }^{8}$

Third, in this paper, when calculating the current value of yearly social security benefits, we use

\footnotetext{
${ }^{8} \mathrm{We}$ are aware that changes in social security to be adopted in the future may reduce benefits or raise taxes for younger cohorts, equivalent to twenty percent of their benefits or more. Without knowing how revisions will be shaped, and if some degree of privatization will be introduced, we have no way of knowing how redistribution will be changed by any remedy that is adopted in the future. Thus we focus on outcomes that are consistent with current social security benefit formulas and taxes, for a generation that is on the verge of retirement.
} 
the mortality tables from the Social Security Administration which are age and gender specific, but do not distinguish the effects of income or race on mortality. We recognize that differences in mortality related to income reduce any redistribution fostered by the social security benefit formula. Members of families with high incomes live longer than members of families with low incomes (e.g., see Duleep, 1989; Panis and Lillard, 1995). Accordingly, our findings will overstate the extent of any redistribution associated with the current social security benefit formula. ${ }^{9}$

Fourth, findings are sensitive to the interest rates employed. For the most part, we use actual interest rates observed to date. To project for the future, we use the intermediate interest rate and wage growth assumptions from the Social Security Administration. ${ }^{10}$

\section{Relation of AIME to Work History and Wage Rates.}

In this section we assess the earnings and work patterns of the age eligible population in the HRS. The unit of observation throughout this section is the individual. All information in the tables assessing patterns of work and earnings is taken solely from the actual social security records from 1951 to $1991 .^{11}$ Only age eligible respondents with actual social security records are analyzed in this section, and only earnings prior to and including 1991 and earnings below the social security maximum

${ }^{9}$ Note, however, that Liebman (1999) finds only modest differences in the rates of return to social security when mortality tables are adjusted for education in addition to sex and race.

${ }^{10}$ If one uses a very low interest rate, it is possible to conclude that, when spouse benefits in high income households are taken into account, the benefit formula is regressive in the way it redistributes within generations. See Steuerle and Bakija (1994).

${ }^{11}$ In particular, the AIME amounts reported in this section are the highest 35 years of earnings through 1991, indexed to 1992 using the social security average earnings index. 
are considered. ${ }^{12}$ The purpose of this section is to analyze the actual pattern of working years and the wages over those working years, without introducing the uncertainties fostered by imputations.

Widows and respondents who had been previously married 10 years or more are treated as married, since their benefits may be affected by the earnings of their former spouses.

\section{A. Averages by Sex, Marital Status, and Primary vs. Secondary Earner.}

First we consider in Table 1 the average values of average indexed yearly earnings (12 times AIME) plus some additional variables measuring years of work and earnings. These are: number of years and average annual earnings in years with non-zero earnings, number of years and average annual earnings in years with significant earnings (a concept to be explained shortly), and lifetime household earnings. The rows report results for the full sample and for subgroups divided by sex and marital status. The last two rows report for the high (primary) earner and low (secondary) earner in a household. The number of observations is the simple count of individual respondents, and the earnings amounts are indexed to 1992 using the social security average annual earnings index and are in thousands of dollars.

More specifically, Column 1 shows the average values of average indexed yearly earnings. The value is around $\$ 15,000$ for all respondents, with average AIME's of around $\$ 23,000$ for males and $\$ 8,000$ for females. The average AIME of unmarried males is considerably less than that of married

\footnotetext{
${ }^{12}$ In calculating household earnings, or in categorizing an earner as a primary or secondary earner in the family, it is occasionally necessary to impute the earnings of the spouse if the spouse (or former spouse, in the case of widowed respondents and divorced respondents whose marriages lasted 10 years or more) does not have a social security record.
} 
males, but the reverse is the case with unmarried females relative to their married counterparts. The second column of Table 1 reports the number of years with nonzero earnings (even if earnings were \$200 from a summer job) and annual earnings in years with nonzero earnings. All age eligible respondents with matched records average 26 years of covered earnings through 1991 (the median is 29 years). Annual earnings in those years average $\$ 17,000$. On average HRS respondents were 56 years old at the time of the HRS survey and were expecting to work about another seven years. At retirement, the AIME should be higher for median respondents by about a quarter. A comparison of the first three columns suggests that the reason that women have only a third the AIME of men is because they work less than two thirds the number of years worked by men, and when they do work, their yearly earnings are half those of men.

To avoid including low-paying summer jobs and similar work in the averages, we introduce the notion of "significant" earnings in Columns 4 and 5. To calculate significant earnings, we first find the average of the highest five years of indexed earnings (in order to mute the effect of a year of very high earnings). Earnings in any particular year are presumed to be significant if the indexed earnings in that year are at least $25 \%$ of this average. Thus for a person with a continuous earnings history, all earnings are deemed to be significant as long as the ratio of high (five year average) to low real earnings is not more than 4 to 1 . Almost a fifth of the earnings years are excluded because they involved very low earnings, and this ratio is slightly larger for women than for men. Correspondingly, average earnings are higher by about a sixth if years with very low earnings are excluded. Again, this ratio is higher for women than for men.

Lifetime earnings of households sum the earnings of men and women in two earner households, 
or include the earnings of the single earner in the case of unmarried individuals. Households with women have about 95 percent of the earnings of households with men, reflecting the lower earnings and greater number of single women than single men.

Although we will not analyze in detail the redistribution from singles to marrieds, there are considerable differences between married and unmarried. Married men have about ten percent more years of covered earnings than unmarried men, and for married men, earnings in years of nonzero earnings are about a quarter higher. Married women have about four fifths of the years of nonzero earnings of unmarried women, and about three fourths of the earnings in years that they worked.

The last two rows of Table 1 report similar statistics for primary vs. secondary earnings. ${ }^{13}$ In married households, the highest earner is denoted as primary, and the spouse is secondary. The earner in single households is considered primary. It is clear from these figures that both work and earnings when working differ considerably between primary and secondary earners. We do not find anything near earnings parity within HRS households. Thus we can very clearly expect the distributions of family earnings to be more concentrated, e.g., to exhibit a lower ratio of standard deviation to the mean, than the distributions of individual earnings.

\section{B. Earnings Measures and Measures of Years of Work by AIME.}

Table 2 begins an examination of years of work and earnings when working among individuals falling in different AIME categories. The first six columns report, by AIME, the same information as in Table 1, and the last column is the weighted percentage of observations falling within the specified

\footnotetext{
${ }^{13}$ In his analysis of distribution, Liebman (1999) arrays families according to the earnings of the primary earner.
} 
AIME range, using HRS weights. Thus, the 1481 respondents in the first row, who have annualized AIME's of from 0 to $\$ 3000$, make up a weighted $19 \%$ of the total of 7370 respondents. Notice from the last column of the table that almost a third of the respondents have annualized AIME's of $\$ 6000$ or less, while the top third have annualized AIME's of $\$ 21,000$ or more. The median AIME lies in the fifth bracket at about $\$ 13,000$ per year at an annualized rate.

As noted above, on average HRS respondents were born in 1936, so they were 56 years old at the time of the HRS survey, and were expecting to work about another seven years. As of 1992, those in the lowest AIME category have only worked 9 years. AIME is calculated on the basis of highest 35 years of earnings, so those in the lowest AIME category worked about a quarter of the years included in the AIME calculation. If they worked another seven years on average, they would end up working for half the period. But given their track record, most of those in this group would work less than that, if at all. The twelve percent of the sample that falls in the second AIME category have worked 18 years. If they worked seven more years, they would end up working two thirds of the 35 years used in calculating AIME. However, they too will probably work a smaller fraction of the 35 year period. Clearly an important reason for having a low AIME is that one has not consistently worked. Even in years when they have worked, workers with low AIME's are less likely to be working "significantly," suggesting that low earners have more uneven earnings streams than high earners. $^{14}$

\footnotetext{
${ }^{14}$ For many individuals, low wages are the result of choosing to work part-time, and/or to interrupt consecutive years of employment with a number of years out of the labor force. Thus significant earnings may understate potential earnings had the individual worked full-time over their adult life.
} 
Low earnings in each year worked are also a cause of low AIME, as is clear from the data in column 2 of the table. As one moves down the lowest five AIME categories, the change in average earnings and the change in years with nonzero earnings appear to be roughly of equal importance in explaining the variation in AIME. From the sixth AIME category on, that is above median AIME, most people will have worked in most years since leaving school, so that the increase in the wage as one proceeds up the AIME categories provides most of the explanation for the increase in AIME.

Lifetime household (family) earnings (husband and wife, or sole earner) are reported in the fifth column of Table 2 by AIME category. Lifetime family earnings include the sum total of all social security covered earnings in the 1951-1991 period, indexed to 1992 by the social security average annual earnings index. For individuals whose spouses did not have social security records, the records were imputed by matching procedures. ${ }^{15}$ For married, widowed, and divorced (with a marriage which lasted at least 10 years) respondents, the household earnings is the sum of the lifetime earnings of the respondent and the spouse.

Lifetime family earnings are not nearly as dispersed as are AIME amounts. They increase from $\$ 620,000$ to $\$ 1,560,000$ from the lowest to highest AIME categories, an increase of only 2.5 times in

${ }^{15}$ The imputed match is done on the basis of gender, cohort, race ( 3 categories), earnings (6 categories), and assets (8 categories), which are available for the spouse even if the spouse was not interviewed. For the match, we look at married respondents who had characteristics which were identical (or as nearly so as we could find) to the characteristics of the non-interviewed spouse. For widows and divorced respondents, we do not have any information about the former spouse, so the match is based on the characteristics of the respondent. In this case, we try to find spouses who were married to individuals with the same gender, cohort, race, and educational attainment (7 categories) as the widowed or divorced respondent. We substitute educational attainment for earnings and assets, since earnings and assets can be significantly affected by the fact of widowhood or divorce. 
lifetime family earnings. There is a corresponding increase in AIME of 24 times from lowest to highest category. This comparison suggests that AIME is a rather poor indicator of lifetime earnings of the household. It also suggests that individuals falling in the bottom AIME category are not as poor as their AIME suggests. Consequently, we can expect that although the social security benefit formula appears to be very progressive, it is going to be less effective in redistributing benefits among families according to lifetime earnings than is suggested by its sharp progressive structure. To be sure, those with fewest years of covered earnings, and lowest earnings when working, fall in the bottom AIME category. But their spouses frequently have higher earnings, and that limits the effectiveness of any redistribution based on AIME of the covered individual.

Table 3 breaks out the results of Table 2 by gender; to avoid unnecessary clutter only the results for significant earnings are presented. As we go down the columns, the years of earnings within each AIME group and average earnings in those years is very similar for the two genders. The major differences are in the last two columns for each group. Almost two thirds of women fall within the lowest three AIME groups, with almost one third falling within the very lowest AIME group, which averages 6 years of significant work and \$6,000 in average earnings in those year. In contrast, only 15 percent of men fall within the lowest three AIME groups. Because the women fall predominantly in the lowest AIME groups, with few years of earnings and low earnings in those years, overall they have 60 percent of the years of significant earnings compared to men, and 50 percent of the earnings in those years, as reported in the last row of the table. These results suggest that when we aggregate the men and women living in the same households to compute a measure of family earnings, the distributions will become relatively narrower. 
The other notable thing about Table 3 is in the lifetime household earnings column. For men, low AIME amounts are associated with very low levels of lifetime household earnings, but for women the household earnings amounts corresponding to low AIME's are much higher. Men with AIME's between 0 and $\$ 3,000$ have lifetime household earnings of only $\$ 170,000$, but women with the same level of AIME have household earnings of almost $\$ 700,000$. This is another indication that women with low AIME's may be married with men with higher earning power, although the same does not seem to be true of men with low AIME's.

\section{The Distribution of Significant Earnings by AIME.}

Table 2 reports average significant earnings by AIME category. Table 4 indicates the distribution of those significant earnings within each AIME category. The entries in the table are percentages of those in the AIME category with the indicated levels of annual significant earnings. Thus, $25 \%$ of the individuals in the $\$ 0-3,000$ annualized AIME bracket had 0 to $\$ 3,000$ of significant earnings in years in which they had positive significant earnings, and $27 \%$ of them had $\$ 3,000$ to $\$ 6,000$ of significant earning in years when they had earnings. The figures in any column of the table add up to 100 percent.

Comparing significant earnings with AIME, there are many observations that appear to have much higher significant earnings than their average indexed earnings, suggesting again that one reason for their low realized earnings is few years of work with significant earnings. Almost half (48 percent) of those with an annualized AIME of 0 to $\$ 3,000$ have significant earnings averaging $\$ 6,000$ or more in each year of work with significant earnings. However, they have significant earnings less than half the time. Of those with annualized AIMEs from $\$ 3000$ to $\$ 6,000,44$ percent have significant earnings of 
$\$ 12,000$ or more, and 4.7 percent have significant earnings of more than $\$ 21,000$. Similar patterns are evident for the next few AIME categories as well. In all of these cases, much higher earnings than is suggested by their AIME goes together with a significant number of years not worked. Another indication of the importance of differences in years of work is the difference between the median value of significant earnings, $\$ 19,400$, and the median AIME of about $\$ 12,600$.

These distributions are sufficiently widespread to suggest that when AIME is used as a basis for redistributing social security benefits, some with high earnings potential are beneficiaries of the resulting redistribution. Significant numbers of workers falling in the low AIME categories have high earnings in years of covered employment. Consequently, many workers falling in the lower AIME categories are there because they work few years, rather than because they have low earnings potential. The result is a disparity between earnings in years of covered work and AIME.

The benefit formula treats generously everyone who is in a low AIME category, regardless of whether the cause is a low level of earnings or few years of work. So a part of the redistribution of social security benefits is from those who work more years to those who work fewer years.

Presumably, those who are falling the in low AIME categories with high earnings potentials are spouses who choose not to participate for many years in the labor market. The next set of results considers the consequences of these participation outcomes for the distribution of family earnings.

\section{Further Details on the Distribution of Family Earnings By AIME.}

Table 5 presents the distribution of lifetime family income grouped by the AIME category of the respondents, as measured by the total indexed social security earnings of both spouses. Note that for a married couple, there will be two entries in the table, one for the AIME level of each spouse. The most 
notable feature of this table, particularly for the lower AIME brackets, is the bimodal distributions of the lifetime household incomes within each AIME bracket. There is a cluster of individuals at the lowest observed level of lifetime household income for each AIME bracket. These are presumably respondents who never married or whose spouses are essentially not working. At a considerably higher level of lifetime household income there is a broader peak of respondents who, although their own AIME is relatively low, are married to individuals with considerably higher lifetime earnings. In the bottom two AIME categories, for example, 15-20\% have lifetime household earnings in excess of $\$ 1,250,000$, which is $25 \%$ above the median lifetime household earnings level of about $\$ 1,000,000$.

Table 6 decomposes the first five columns of Table 5 by gender. Among the women, the same bimodal distribution is evident, if anything even more pronounced. Among the men, however, the bimodal distribution essentially disappears. For men who have low levels of AIME, only a relatively small number have lifetime household earnings that are very high. Relatively few men are in these categories, with only $15 \%$ having annualized AIME levels of less than $\$ 9,000$, but those men are likely

to live in households with very limited lifetime resources. The same is not true for women. The majority of women are in the lowest three AIME brackets, but most of them have fairly high family lifetime earnings.

\section{Redistribution of Social Security Taxes and Benefits Among Individuals and Families.}

The next set of results deals with distributions of social security taxes and benefits. Since in this section we are more concerned with redistribution, rather than with distributions of work and earnings, we felt that it was important to include the full sample in these calculations. Hence, we include all age 
eligible respondents, regardless of whether they had a social security record or not, and we impute records for those for whom none was obtained. ${ }^{16}$ Further, these results use earnings which are projected beyond 1991 until the individual's indicated expected retirement age ${ }^{17}$. The AIME figures reported in this section are the real value of the expected actual AIME. Nominal earnings amounts are indexed by the social security average annual earnings index up to age 60, as specified in the AIME calculation rules, and the value of the nominal AIME is adjusted from age 62 to 1992 using the Social Security Administration's projected inflation rate.

\section{A. Alternative Measures of Redistribution.}

Table 7 presents baseline results for all age eligible respondents using own benefits and taxes. Each column of figures pertains to ten percent of the covered individuals, with the deciles defined

${ }^{16}$ Specifically, we used starting date on their current job, starting and ending dates for their last jobs (i.e., the job last held by those not working in 1992), a previous 5 year job, and up to two other jobs with pensions. Respondents were also asked about final earnings on those jobs. In addition, we used information in Wave 3 about the date of entry into the labor force, how many years were worked before the date the previous job was secured, and how many years of work were in jobs covered by social security. Earnings for other years are estimated by adjusting observed earnings on the basis of experience. The coefficients for experience, based on data from the Survey of Consumer Finances, are: experience .0138 , experience squared -.000283, and experience * education .000996 (Anderson, Gustman and Steinmeier, 1999).

${ }^{17}$ Future earnings are projected by assuming that real earnings observed in the last year in the 1991 will persist until the respondent's expected retirement date. If the respondent has no earnings in 1991, zeros are projected for future years. If the expected retirement age was greater than 70, or if the individual indicated that he never expected to retire, a retirement age of 70 was used unless the individual had already worked beyond that age in 1992. If the respondent did not provide an expected retirement age, an age of 62 was used, again unless the respondent had already worked beyond that age. 
according to place in the distribution of AIME. ${ }^{18}$ The first two rows are ex ante expected taxes and expected benefits. To calculate these figures, the taxes and benefits each year are adjusted for the probability of collecting them. ${ }^{19}$ The resulting figures are then indexed to 1992 using the 10 year government bond rate if the year is before 1992, or the Social Security Administration's projected interest rate if the year is after 1992. Finally, the adjusted taxes are added to get the figures in the table, and the same is done for benefits. Taxes and benefits are measured in thousands of 1992 dollars, and Table 7 includes results for all eligible respondents.

The last column of the table indicates that for the HRS cohort, on average social security taxes will exceed benefits. The difference is about $\$ 15,000$ per age eligible HRS respondent. ${ }^{20}$ We use the current law, rather than a hypothetical law revised to restore financial balance in the system, as the baseline in judging the current amount of redistribution. ${ }^{21}$ Reflecting the progressivity of the benefit

${ }^{18}$ Table 7 and those that follow group the population by AIME decile, which is a change from the first 6 tables. The earlier tables address the question of how hours and earnings are distributed in each AIME category, and having even dollar brackets facilitates that discussion. However, the distributional issues discussed in Tables 7 to 10 are most easily understood if the population is grouped into deciles.

${ }^{19}$ The taxes and benefits are calculated ex-ante from the time the individual starts paying taxes.

${ }^{20}$ Because taxes are collected on average 30 years or so earlier than benefits are paid, this amount is extremely sensitive to the exact series used to discount taxes and wages to a common date.

${ }^{21}$ As noted earlier, if efforts to fix the insolvency of the system are adopted soon enough, the shortfall of benefits below taxes in Table 5 may understate the shortfall between benefits and taxes experienced by the HRS cohort. But the HRS cohort is old enough that its members may not experience a further reductions in social security benefits. Without knowing how revisions will be shaped, and if some degree of privatization will be introduced, we have no way of knowing how redistribution will be changed by any remedy that is adopted. Using similar reasoning, it will be dangerous to project the experience of the HRS cohort onto younger cohorts without making significant adjustments. 
formula, respondents' benefits exceed taxes through the bottom half of the income distribution. For the upper half of the distribution by AIME, taxes exceed benefits, by increasing amounts as we move through the deciles. The lowest decile does not have more than $\$ 500$ in either taxes or benefits because if they have worked at all, they generally will not have worked more than the 10 years necessary to entitle them to benefits.

The next two rows are measures of redistribution within the deciles. The gini coefficients are based on a diagram where the horizontal axis is the cumulative weighted taxes, and the vertical axis is the cumulative weighted benefits. The gini coefficient for the first decile is omitted since few taxes are paid or benefits received for this group. From the second decile on, the gini coefficients fall gradually, suggesting that the amount of redistribution within AIME categories declines with higher incomes. The gini coefficient in the last column, which measures redistribution among the entire population, reflects the redistribution among the various deciles, and is higher than the coefficients within the individual deciles.

The next row is an alternative measure of redistribution within the column group. To get these figures, the actual benefits of each individual are compared to the benefits that individual would have received if benefits were the same proportion of taxes as they are for that group. If the actual benefits are more than the pro-rata benefits, given the taxes, we can say that benefits were redistributed to this individual from other members of the group. The difference between the actual benefits and the prorata benefits is a measure of the amount of redistribution to (from) this individual. The values reported in the table for this row are the sum of the redistributions for all individuals who had positive redistributions, divided by the total benefits for the group in the column. This measure is essentially the maximum gap between the gini curve and the $45 \%$ line in the diagram for the gini coefficient. A figure 
of $10 \%$ means that of the total benefits received by the group, $10 \%$ would have to be redistributed from some individuals of the group to other individuals in order for everyone to receive the same ratio of benefits to taxes paid. The values reported in this row have a similar pattern to the one observed for the gini coefficient. The value of $14.1 \%$ in the last column means that for the entire population, the amount of redistributed benefits amounts to $14.1 \%$ of total benefits.

The next two rows of the table measure redistribution among the various deciles. The first of these two rows compares actual benefits of the group to the benefits that would have been received if benefits were simply pro-rated to taxes for the entire population. This measure of redistribution is a measure of net redistribution to the decile. For instance, the value of $37 \%$ in the fourth decile means that the actual benefits of that decile are $37 \%$ higher than would be the case if benefits were proportional of taxes for the entire population. This $37 \%$ obviously comes at the expense of other deciles. Again, this measure is essentially meaningless for the first decile, which pays few taxes and receives almost no benefits. In the second and third deciles, over half of the benefits received by those in those deciles are due to redistribution of benefits from other deciles. On the other hand, those in the top AIME decile receive 33\% less than their pro-rata share of taxes; those benefits are redistributed to those in other deciles.

The row labeled as "Share of Total Redistribution@ looks at redistribution to those in the AIME decile in another light. The previous row expressed the net redistribution to the group as a percentage of total benefits to the group, but this row expresses the net redistribution to the group as $a$ percentage of the total amount redistributed for all individuals. The share of redistribution rises between the second and third deciles principally because the benefit amounts are larger in the third 
decile, but from the third decile on, the share of redistribution measure again declines as AIME increases. The top two deciles provide almost two-thirds of the total amounts redistributed. The redistribution is slightly negative for the first decile because this decile pays some taxes but almost never receives benefits because they do not have the requisite 10 years of work. Another point of note in this row is that the positive amounts (as do the negative amounts) sum to about $76.5 \%$. This means that almost three quarters of the total redistribution is among the deciles, with only a quarter redistributed within the deciles.

The final rows of the table give percentiles for internal rates of return. Before calculating these rates, the taxes and benefits are indexed to 1992 using the historical CPI or the projected social security inflation rate. That means that these rates are effectively real rates. To get these figures, each individual in the group has a real internal rate of return calculated. These rates are then arrayed by value, and the (weighted) percentiles are found by picking the appropriate spot in the distribution. An examination of these figures reveals that when the benefits approximately equal taxes in the previous rows, the internal rates of return are approximately 3.0\%. Another way to interpret this is that the average of the historical real returns for the HRS cohort has been approximately $3.0 \%$. Note also that the percentage of observations is a weighted percentage, as in the previous tables. On average, these

real rates of return are 4.8 percent for those in the $90^{\text {th }}$ percentile of returns, to 0.4 percent for those in the $10^{\text {th }}$ percentile of returns. The distributions of returns decline as expected as AIME increases.

\section{B. Measures of Redistribution Using Individual and Family Benefits and Individual AIME}

\section{Distribution.}

Table 8 reports benefits redistributed shares, gini coefficients, and median rate of return. The 
first row simply repeats some of the results from the final column of Table 7. The next two rows split the results into men and women separately. The second section reports results when benefits include, in addition to own benefits, spouse and survivor benefits, while the third section counts social security benefits and taxes for both spouses in the household. ${ }^{22}$ Each section takes us another step toward considering redistribution at the level of the family.

The first column of Table 8 gives amount of redistribution among all individuals in the group. For the first row, redistribution is measured among all respondents in the sample. The second and third rows suggest that there is less redistribution within the groups of men and women taken separately than for all respondents. The reason is that much of the redistribution based on own benefits is from men to women, because, as we have seen above, the AIMEs for women are consistently lower than they are for men. ${ }^{23}$

The second section of the table suggests that there is less redistribution among all individuals

${ }^{22}$ More specifically, the first section uses only the social security taxes, including the employer share but excluding the medicare taxes, and the benefits that the respondent will collect on the basis of his or her own earnings. The second set uses the same taxes but includes the benefits that the spouse will collect on the basis of the respondents earnings over and above the benefits that the spouse would collect anyway based on the spouse's own earnings. The third set of calculations sums the ex ante taxes and total benefits of the two partners, even if one of the partners has died or if the partners are divorced, as long as they were married for 10 years or more. This treats married and widowed/divorced respondents on an equal ex ante basis, and does not treat differently the woman whose husband dies one year before the survey differently from the women whose husband dies one year after the survey. We impute former husband's earnings based on individuals matched via the process described in footnote 15.

${ }^{23}$ When we recalculate Table 5 separately for men and women, we find that for men, taxes paid (1150) exceed benefits (765) by a wide margin. For women, taxes (448) fall short of benefits (513), indicating that women benefit from redistribution. On average their benefits are increased 29 percent, and they receive 88 percent of all benefits redistributed, while men donate 22 percent of their benefits to accomplish this redistribution. 
when own and spouse benefits are taken into account. As suggested by the earlier literature, high AIME respondents apparently benefit disproportionately from spouse and survivor benefits, suggesting their spouses have lower earnings relative to their own. Notice that there is little change within the men's and women's groups when own and spouse benefits are taken into account. It is the apparent redistribution among all individuals, and again importantly from men to women, that is reduced when own and spouse benefits are counted. Finally, the amount of redistribution declines again when family benefits are attributed to each respondent. ${ }^{24}$ What is happening here is that within the household, the redistribution towards spouses who worked part of their lifetimes are offset by the redistribution away from the husband. The redistribution to single women from men is not netted out, however, and this means that there is more redistribution when all respondents are grouped than within the groups of men and women alone.

The second column of the Table 8 presents gini coefficients. Benefits and taxes are more unequally distributed among women than men. When all respondents are pooled, the amount of inequality between benefits and taxes, and thus the amount of redistribution, declines when own and spouse benefits are counted. There is a further decline, particularly among women, when family benefits and taxes are attributed to each respondent.

The last column 8 indicates median rates of return by sex and type of benefit. Reflecting the greater redistribution to women, from row 1 we see that rates of return to social security are almost

\footnotetext{
${ }^{24}$ Since the family redistributions are identical for husbands and wives, the weights of married (and widowed or divorced) respondents are given half weight in order to avoid double counting of these redistributions
} 
twice as high for women than men. When spouse and survivor benefits are taken into account and attributed to the earner who is responsible, the rates of return increase within the group of all respondents and within the group of men. There is no change within the group of women because, by and large their husbands' earnings are higher than their own earnings, and as a result, there is little value to the spouse and survivor benefits they accrue. Taking family benefits into account slightly increases the rate of return for men and for all, and reduces the rate of return for women.

\section{Measures of Redistribution Using Individual and Family AIME Distributions.}

Table 9 reports the redistribution to those falling in each decile group, under various definitions of the group and of relevant benefits. The redistribution is measured as the percentage of benefits accruing to the decile which have been redistributed from other deciles, so that the first row of Table 9 simply repeats the fifth row of Table 7. The first panel of Table 9 uses the annualized AIME of the individual, while the second panel combines this with the annualized AIME of the spouse if the respondent is married, widowed, or divorced. Within each panel, redistribution to the decile is reported first on the basis of own benefits and taxes, second using a definition that also adds spouse and survivor benefits based on the respondent's own earnings, and third on the basis of family benefits and taxes for each respondent.

Looking at the top panel of the table, we find much less redistribution moving from the top row, where we report the redistribution according to the simple social security formula, to the third row, which reports redistribution using total family benefits. For those in the second to sixth deciles, the redistribution declines sharply between the first row and the third row, and in particular from the second row to the third row, where family benefits are considered. As with Table 8, the introduction of family 
benefits causes the high redistribution to at least some low AIME women to be offset by the redistribution away from their spouses, reducing the net redistribution. In the second decile, this effect reduces redistribution from a half of benefits to a quarter, and in the third to fifth deciles, the share of benefits due to redistribution falls by a fifth of total benefits or more. However, in the top two deciles, the principal reduction in redistribution occurs when we add spouse and survivor benefits. In these deciles the spouse and survivor benefits are most valuable, since they accrue primarily to higher wage individuals whose spouses have relatively low AIME's.

In the bottom panel of the table, regrouping the deciles according to family AIME's, which are roughly equivalent to lifetime family earnings, there are two findings of note. ${ }^{25}$ First, the pattern of changes when we add spouse and survivor benefits, and then family benefits, essentially reproduces the pattern in the top panel. This indicates that the same processes which produced the pattern in the top panel continues to operate even when we look at lifetime family income rather than lifetime individual income. However, the levels of redistribution in the bottom panel are almost always lower than in the top panel. The deciles in the bottom panel are simply a reshuffling of the same respondents in the top panel, except that in the reshuffing some high AIME individuals are coupled with lower AIME individuals, and vice versa. In this regard, note that the distribution of family AIME amounts is relatively

25 The observations in this table are still individuals, although they are now classified by family AIME. In some results, Liebman (1999) classifies families based on the AIME for the high earner; in others he classifies families based on the AIME for the total covered earnings of both spouses. In the latter case, he divides both taxes and benefits evenly among each spouse, a treatment that by itself would generate tables that, during the period of the marriage, are analogous to the tables we construct that report redistribution based on family AIME. 
narrower than the distribution of individual AIME amounts. ${ }^{26}$ This process also reshuffles some individuals with high individual AIME's and high losses from redistribution to deciles lower in the family AIME distribution, thereby tending to reduce the redistribution among the deciles. As can be seen when we compare the redistribution observed in the top row of Panel A of Table 9 with the bottom row of Panel B, the measured redistribution is halved when respondents are grouped by their family's AIME, and benefits and taxes are considered at the family level, rather than when individuals are ordered by their own AIME and only individual benefits are considered.

\section{Redistribution When Families Are Classified By Earnings Capacity (Significant Earnings).}

Table 10 reports on benefits lost or gained as a result of redistribution when respondents are grouped by earnings capacity, as measured by“significant earnings". ${ }^{27}$ The AIME measures of Tables 7 to 9 are roughly proportional to realized lifetime earnings, while significant earnings are roughly proportional to potential lifetime earnings. The two concepts differ because not all potential earnings

${ }^{26}$ For instance, the gap between the $25^{\text {th }}$ and $75^{\text {th }}$ percentiles of individual AIME's is from about $\$ 6,000$ to about 28,000 , or 4.5 to 1 , while the similar gap of family AIME's is from about $\$ 11,000$ to about $\$ 39,000$, or 3.5 to 1 .

${ }^{27}$ As before, "significant" earnings are $25 \%$ or more of the average of the 5 highest earnings years, after adjustment to 1992 dollars using the CPI. The combined total significant annual earnings is simply the sum of the annual earnings of the husband and the wife. All of the earnings figures in Table 10 include all earnings, not just covered earnings or those below the social security maximum earnings amount. 
will be realized if the respondent has extended periods not working. ${ }^{28}$ In the first panel of Table 10 , each respondent is ordered according to the individual respondent's "significant earnings". The second panel orders respondents by the "significant earnings" for the respondent's family. ${ }^{29}$

As we have seen earlier, especially for those in the lower deciles, their significant earnings are much higher than their AIME. That is, many of those with a low AIME have not worked many years, but when they did work, their yearly earnings were much higher than their AIME suggests. As a result, the brackets for the bottom deciles of earners in Table 10 are much wider than the brackets in Table 9.

Compared to the top panel of Table 9, the redistribution percentages in the top panel of Table 10 appear to be slightly less. This occurs because some individuals with low realized AIME's nevertheless have higher potential earnings, and therefore higher "significant" earnings. These individuals, who receive positive amounts of redistribution, are reshuffled to higher deciles when significant earnings are considered, and therefore tend to dilute the negative redistributions in those deciles. This in turn reduces the measured extent of redistribution among deciles when significant earnings are considered.

However, the major finding of Table 10 comes in looking at the bottom row of the bottom panel. This row looks at family taxes and benefits for individuals grouped according to the potential

${ }^{28}$ For example, if the wife earns $\$ 40,000$ for 7 years, her significant annual earnings are $\$ 40,000$ even if she is out of the labor force for the other years.

${ }^{29}$ Coronado, Fullerton and Glass (1999a) order families based on full family earnings, which assumes that each spouse works full time at the wage observed when they were working. We obtain the same ordering among families when we use "significant earnings" for the family to order families by their earnings capacity. They also make an alternative calculation where they use the average wage for the sample to value leisure at the same price across each individual. 
earnings of the family. Compare this to the first row of Table 9, which looks at the individual taxes and benefits according to the actual earnings of the individual. The redistribution figures in the bottom row of Table 10 appear to be roughly a quarter of the corresponding figures in the top row of Table 9. The implication is that when family taxes and benefits are used, and when respondents are grouped according to their total potential family income, the redistribution among deciles is dramatically reduced. That is, the amount of redistribution from families with high potential income to families with low potential income, the type of redistribution that most of us think about when we talk about redistribution, is much lower than an analysis grouping individuals according to individual realized earnings would suggest. Instead, much of the redistribution among families based on potential family income must occur within deciles. The obvious candidate is transfers from families with two earners to traditional families with roughly the same combined earning power but in which only one spouse is a lifetime worker.

Figure 1 uses rates of return to summarize these results. The top panel shows the strong redistribution when deciles are computed according to each respondent's AIME, and also shows the $25^{\text {th }}$ to $75^{\text {th }}$ percentile range of the rates of return within each decile. In the second panel, where individuals are grouped by family AIME, the solid line becomes flatter, corresponding to the finding above that almost half the redistribution fostered by the social security benefit formula is eliminated when we evaluate redistribution on a family rather than on an individual basis. In the third panel, where families are grouped according to their significant earnings, the system redistributes hardly at all. Virtually all of the redistribution is within deciles rather than between deciles. Taken together these results suggest that whatever redistribution exists under the current system is largely redistribution 
among families with similar potential earnings capacities and benefits traditional families with a spouse who chooses not to work.

\section{Conclusion.}

This paper has investigated the extent to which the social security benefit formula redistributes benefits from high to low earners. The extent of redistribution that is found depends on how one defines high earners. The benefit formula clearly redistributes own benefits from own taxes when incomes are measured for each individual by own AIME. Much of the redistribution at the individual level is from men to women. The extent of redistribution is halved, however, when benefits and taxes for both spouses are analyzed at the level of the family. Moreover, the remaining redistribution is mostly from families that have spent many years in the labor force to those with fewer years of work. Thus when we array families by earnings in years that they work, which is a measure of potential earnings, we find that the benefit formula redistributes very little from families with high earnings potential to families with low earnings potential.

A direct examination of the social security benefit formula, and a finding that benefits are redistributed from high to low earners when people are classified according to own AIME, might suggest to policy makers that the current system is highly redistributive. One might then believe that there is a considerable potential cost in terms of foregone redistribution to going from the present system to an alternative that does not explicitly redistribute, e.g., to a system of national retirement accounts that is neutral with regard to redistribution. However, our evidence suggests that it is a mistake to argue for the current social security benefit formula on the grounds that it is highly 
redistributive from families with high earnings potential to families with lower potential. A better argument could be made if the focus were on redistributing from two earner families to traditional families with one earner and a stay-at-home spouse.

Without repeating all of the caveats mentioned earlier, it is appropriate to end with a word of caution. The results presented in this paper pertain only to a single cohort, those born from 1931 to 1941. Further investigation is required before these findings can be generalized to the cohorts that will follow. Nevertheless, it is clear from these results that the general perception that a great deal of redistribution from the rich to the poor is accomplished by the progressive social security benefit formula is greatly exaggerated. As a result, adoption of a social security scheme with individual accounts designed to be neutral with regard to redistribution would make much less difference to the distribution of social security benefits and taxes among families with different earnings capacities than is commonly believed. ${ }^{30}$

${ }^{30}$ Feldstein and Liebman (1999) discuss features of a system of individualized accounts that would foster redistribution. 


\section{References}

Anderson, Patricia M., Alan L. Gustman and Thomas L. Steinmeier. 1999. "Trends in Male Labor Force Participation and Retirement: Some Evidence on the Role of Pension and Social Security in the 1970s and 1980s". Journal of Labor Economics 17(4), Part 1: 757-783.

Coronado, Julia Lynn, Don Fullerton and Thomas Glass. 1999a. "Distributional Impacts of Proposed changes to the Social Security System”. Tax Policy and the Economy 13: 149-186.

1999b. "Long Run Effects of Social Security Reform Proposals on Lifetime Progressivity". Paper presented at NBER conference on Distributional Aspects of Social Security and Social Security Reform. October.

Cutler, David M. “Comment”. In M. Feldstein, editor, Privatizing Social Security. Chicago: University of Chicago Press for NBER, pp. 357 - 361.

Duleep, Harriet. 1989. Measuring Socioeconomic Mortality Differentials Over Time. Demography 26 (May): 345-51.

Feldstein, Martin and Jeffrey Liebman. 1999. "The Distributional Effects of an Investment Based Social Security System". Paper presented at NBER conference on Distributional Aspects of Social Security and Social Security Reform. NBER Working Paper 7492.

Gustman, A., O. Mitchell, A. Samwick, and T. Steinmeier. 1999. "Pension and Social Security Wealth In The Health And Retirement Study". In J. Smith and R. Willis, editors. Wealth, Work and Health, Innovations in Measurement in the Social Sciences. Ann Arbor: University of Michigan Press, pp. 150-207.

Gustman, A. and T. Steinmeier. 1998. "Privatizing Social Security: First Round Effects of A Generic, Voluntary, Privatized U.S. Social Security System". In M. Feldstein, editor, Privatizing Social Security. Chicago: University of Chicago Press for NBER, pp. 313 - 357.

. 1999. "What People Don't Know About Their Pensions and Social Security: An Analysis Using Linked Data From the Health and Retirement Study”. NBER Working Paper 7368.

2000. "Social Security Benefits of Immigrants and Native Born". In

George Borjas, editor, Issues in the Economics of Immigration. Chicago: University of Chicago Press for NBER, pp. 309-350. 
Haider, Steven and Gary Solon. 1999. "Evidence of Non-Response Bias in the HRS Social Security Files". Xerox. Ann Arbor, Michigan.

Liebman, Jeffrey B. 1999. "Redistribution in the Current U.S. Social Security System". Paper presented at NBER conference on Distributional Aspects of Social Security and Social Security Reform. October.

Olson, Jan. Forthcoming. "Linkages with Data from SSA Records in the Health and Retirement Study". Social Security Bulletin.

Panis, Constantijn W.A. and Lee A. Lillard. 1995. "Socioeconomic Differentials in the Return to Social Security. Santa Monica: Rand, January.

Smith, James P. "The Distribution of Family Earnings". Journal of Political Economy 87(5) Part 2: S163-S192.

Social Security Administration. 1999. Annual Statistical Supplement to the Social Security Bulletin. Washington, D.C.: Social Security Administration.

Steuerle, C. Eugene and Jon M. Bakija. 1994. Retooling Social Security for the $21^{\text {st }}$ Century: Right and Wrong Approaches to Reform. Washington, D.C.: Urban Institute. 
Table 1

Earnings and Years of Work By Sex, Marital Status and Type of Earner

\begin{tabular}{|c|c|c|c|c|c|c|c|}
\hline & & $\begin{array}{r}\mathrm{Ye} \\
\text { Nonze }\end{array}$ & $\begin{array}{l}\text { ith } \\
\text { rnings }\end{array}$ & $\begin{array}{r}Y \\
\text { Signific }\end{array}$ & $\begin{array}{l}\text { vith } \\
\text { arnings* }\end{array}$ & & \\
\hline & $\begin{array}{l}\text { Annualized } \\
\text { AIME }\end{array}$ & $\begin{array}{l}\text { Number } \\
\text { of Years }\end{array}$ & $\begin{array}{c}\text { Annual } \\
\text { Earnings }\end{array}$ & $\begin{array}{l}\text { Number } \\
\text { of Years }\end{array}$ & $\begin{array}{l}\text { Average } \\
\text { Earnings }\end{array}$ & $\begin{array}{l}\text { Lifetime } \\
\text { Household } \\
\text { Earnings }\end{array}$ & $\begin{array}{l}\text { Number of } \\
\text { Observations }\end{array}$ \\
\hline All Respondents & $\$ 15 \mathrm{~K}$ & 26 & $\$ 17 \mathrm{~K}$ & 22 & $\$ 20 \mathrm{~K}$ & $\$ 980 \mathrm{~K}$ & 7370 \\
\hline Males & 23 & 32 & 24 & 27 & 27 & 1010 & 3389 \\
\hline Females & 8 & 21 & 12 & 16 & 14 & 960 & 3981 \\
\hline Married Males & 23 & 32 & 24 & 28 & 28 & 1050 & 3067 \\
\hline Married Females & 8 & 20 & 11 & 16 & 14 & 1010 & 3602 \\
\hline Unmarried Males & 16 & 29 & 18 & 27 & 21 & 570 & 322 \\
\hline Unmarried Females & 12 & 25 & 15 & 21 & 17 & 440 & 379 \\
\hline Primary Earners & 20 & 31 & 22 & 26 & 25 & 870 & 4403 \\
\hline Secondary Earners & 7 & 10 & 11 & 15 & 14 & 1140 & 2967 \\
\hline
\end{tabular}


Table 2

Earnings and Years of Work By AIME Group

\begin{tabular}{|c|c|c|c|c|c|c|c|}
\hline & \multicolumn{2}{|c|}{$\begin{array}{l}\text { In Years with } \\
\text { Nonzero Earnings }\end{array}$} & \multicolumn{2}{|c|}{$\begin{array}{l}\text { In Years with } \\
\text { Significant Earnings* }\end{array}$} & \multirow[b]{2}{*}{$\begin{array}{l}\text { Lifetime } \\
\text { Household } \\
\text { Earnings }\end{array}$} & \multirow[b]{2}{*}{$\begin{array}{c}\text { Number of } \\
\text { Observations }\end{array}$} & \multirow[b]{2}{*}{$\begin{array}{c}\text { Percent of } \\
\text { Observations }\end{array}$} \\
\hline & $\begin{array}{l}\text { Number } \\
\text { of Years }\end{array}$ & $\begin{array}{l}\text { Annual } \\
\text { Earnings }\end{array}$ & $\begin{array}{l}\text { Number } \\
\text { of Years }\end{array}$ & $\begin{array}{l}\text { Average } \\
\text { Earnings }\end{array}$ & & & \\
\hline \multicolumn{8}{|l|}{ Annualized AIME } \\
\hline$\$ 0-3 K$ & 9 & $\$ 5 \mathrm{~K}$ & 6 & $\$ 6 \mathrm{~K}$ & $\$ 620 \mathrm{~K}$ & 1481 & $19 \%$ \\
\hline $3-6$ & 18 & 9 & 13 & 12 & 730 & 919 & 12 \\
\hline $6-9$ & 24 & 12 & 18 & 15 & 830 & 719 & 9 \\
\hline $9-12$ & 27 & 14 & 21 & 18 & 900 & 638 & 8 \\
\hline $12-15$ & 30 & 16 & 24 & 20 & 980 & 531 & 7 \\
\hline $15-18$ & 32 & 19 & 26 & 22 & 1000 & 454 & 6 \\
\hline $18-21$ & 33 & 21 & 28 & 25 & 1050 & 410 & 5 \\
\hline $21-24$ & 35 & 23 & 30 & 27 & 1110 & 408 & 6 \\
\hline $24-27$ & 35 & 26 & 31 & 29 & 1210 & 386 & 5 \\
\hline $27-30$ & 36 & 29 & 32 & 32 & 1260 & 391 & 6 \\
\hline $30-33$ & 36 & 31 & 33 & 34 & 1410 & 429 & 7 \\
\hline $33-36$ & 37 & 33 & 33 & 37 & 1470 & 367 & 6 \\
\hline $36+$ & 39 & 35 & 36 & 38 & 1560 & 237 & 4 \\
\hline All Respondents & 26 & 17 & 22 & 20 & 980 & 7370 & 100 \\
\hline
\end{tabular}

*Significant earnings are indexed yearly earnings that amount to at least 25 percent of the average of the high five years of indexed earnings. 
Table 3

Earnings and Years of Work By AIME Group and Gender

\begin{tabular}{|c|c|c|c|c|c|c|c|c|}
\hline & \multicolumn{4}{|c|}{ Males } & \multicolumn{4}{|c|}{ Females } \\
\hline & \multicolumn{2}{|c|}{$\begin{array}{c}\text { In Years with } \\
\text { Significant Earnings* }\end{array}$} & \multirow[b]{2}{*}{$\begin{array}{l}\text { Lifetime } \\
\text { Household } \\
\text { Earnings }\end{array}$} & \multirow[b]{2}{*}{$\begin{array}{c}\text { Percent of } \\
\text { Obser- } \\
\text { vations }\end{array}$} & \multicolumn{2}{|c|}{$\begin{array}{c}\text { In Years with } \\
\text { Significant Earnings* }\end{array}$} & \multirow[b]{2}{*}{$\begin{array}{l}\text { Lifetime } \\
\text { Household } \\
\text { Earnings }\end{array}$} & \multirow[b]{2}{*}{$\begin{array}{c}\text { Percent of } \\
\text { Obser- } \\
\text { vations }\end{array}$} \\
\hline & $\begin{array}{l}\text { Number } \\
\text { of Years }\end{array}$ & $\begin{array}{c}\text { Annual } \\
\text { Earnings }\end{array}$ & & & $\begin{array}{l}\text { Number } \\
\text { of Years }\end{array}$ & $\begin{array}{l}\text { Annual } \\
\text { Earnings }\end{array}$ & & \\
\hline Annualized AIM & & & & & & & & \\
\hline$\$ 0-3 K$ & 7 & $\$ 8 \mathrm{~K}$ & $\$ 170 \mathrm{~K}$ & $5 \%$ & 6 & $\$ 6 \mathrm{~K}$ & $\$ 690 \mathrm{~K}$ & $31 \%$ \\
\hline $3-6$ & 12 & 14 & 280 & 5 & 14 & 12 & 840 & 18 \\
\hline $6-9$ & 16 & 17 & 430 & 5 & 19 & 14 & 950 & 14 \\
\hline $9-12$ & 20 & 18 & 510 & 6 & 21 & 17 & 1070 & 11 \\
\hline $12-15$ & 24 & 20 & 660 & 6 & 25 & 19 & 1180 & 8 \\
\hline $15-18$ & 26 & 22 & 770 & 7 & 26 & 23 & 1220 & 6 \\
\hline $18-21$ & 28 & 24 & 880 & 7 & 28 & 25 & 1310 & 4 \\
\hline $21-24$ & 30 & 27 & 980 & 9 & 30 & 26 & 1440 & 3 \\
\hline $24-27$ & 31 & 29 & 1150 & 9 & 30 & 30 & 1490 & 2 \\
\hline $27-30$ & 32 & 32 & 1230 & 11 & 32 & 32 & 1450 & 2 \\
\hline $30-33$ & 33 & 34 & 1380 & 13 & 30 & 37 & 1730 & 1 \\
\hline $33-36$ & 33 & 37 & 1460 & 12 & 34 & 35 & 1650 & 1 \\
\hline $36+$ & 36 & 38 & 1560 & 8 & 36 & 37 & 1700 & 0 \\
\hline All Respondents & 27 & 27 & 1010 & 100 & 16 & 14 & 960 & 100 \\
\hline
\end{tabular}

*Significant earnings are indexed yearly earnings that amount to at least 25 percent of the average of the high five years of indexed earnings. 
Table 4

Distribution of Significant Earnings Within AIME Categories*

Annualized AIME

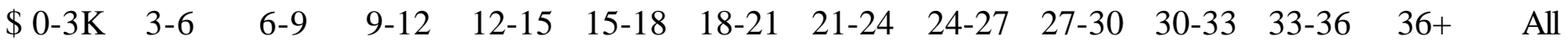

Level of Significant

Earnings*

\$ $0-3 \mathrm{~K}$

3- 6

6- 9

9-12

$12-15$

$15-18$

$18-21$

21-24

24-27

27-30

$30-33$

33-36

36-39

$39-42$

$42+$

Column Total

$\begin{array}{lll}25 \% & & \\ 27 & 3 \% & \\ 26 & 24 & 5 \% \\ 13 & 29 & 26\end{array}$

$\begin{array}{llll}13 & 29 & 26 & 6 \%\end{array}$

$\begin{array}{llll}5 & 20 & 29 & 26\end{array}$

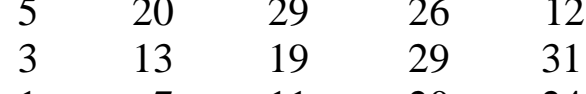

$\begin{array}{lll}7 & 11 & 20\end{array}$



1

2
1

Observations

$19 \%$

$12 \% \quad 12$

5
2
1

9
3
2
1

17
8
4
3
1

*Significant earnings are indexed yearly earnings that amount to at least 25 percent of the average of the high five years of indexed earnings. 
Table 5

Distribution of Lifetime Household Earnings Within AIME Categories

Annualized AIME

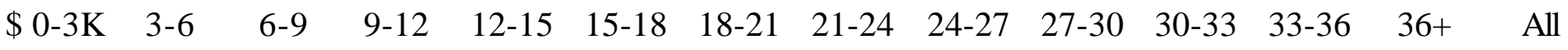

Lifetime Household

Earnings Level

\$ $0-100 \mathrm{~K}$

$100-200$

200-300

$300-400$

$400-500$

$500-750$

$750-1000$

$1000-1250$

$1250-1500$

1500-2000

$2000+$

Column Total

Percent of

Observations

\begin{tabular}{|c|c|c|c|c|c|c|c|c|c|c|c|c|c|}
\hline $28 \%$ & & & & & & & & & & & & & 3 \\
\hline 6 & $27 \%$ & & & & & & & & & & & & 2 \\
\hline 5 & 6 & $24 \%$ & & & & & & & & & & & \\
\hline 4 & 4 & 9 & $24 \%$ & & & & & & & & & & \\
\hline 4 & 4 & 5 & 12 & $21 \%$ & & & & & & & & & 4 \\
\hline 11 & 10 & 11 & 12 & 24 & $46 \%$ & $38 \%$ & $3 \%$ & & & & & & 12 \\
\hline 13 & 11 & 11 & 9 & 13 & 15 & 24 & 51 & $40 \%$ & $12 \%$ & & & & \\
\hline 15 & 15 & 12 & 9 & 7 & 9 & 11 & 20 & 24 & 48 & $36 \%$ & $19 \%$ & & 1 \\
\hline 14 & 19 & 17 & 17 & 14 & 9 & 7 & 9 & 16 & 24 & 36 & 45 & $52 \%$ & \\
\hline 1 & 4 & 11 & 17 & 22 & 20 & 18 & 12 & 15 & 12 & 22 & 32 & 42 & \\
\hline & & & & & 1 & 3 & 5 & 5 & 3 & 7 & 5 & 6 & \\
\hline
\end{tabular}



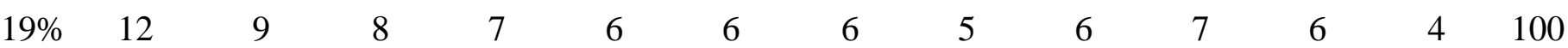


Table 6

Distribution of Lifetime Household Earnings Within Lower AIME Categories By Gender

Males

Annualized AIME

Lifetime Household

Earnings Level

$\$ 0-100 \mathrm{~K}$

$100-200$

200-300

$300-400$

400-500

$500-750$

$750-1000$

$1000-1250$

$1250-1500$

$1500-2000$

$2000+$

Column Total

Percent of

Observations

\$ 0-3K $\quad 3-6 \quad 6-9 \quad 9-12 \quad 12-15 \quad$ All

$\begin{array}{cccccc}58 \% & & & & & 3 \% \\ 16 & 53 \% & & & & 3 \\ 10 & 18 & 38 \% & & & 3 \\ 2 & 10 & 25 & 36 \% & & 4 \\ 4 & 8 & 11 & 27 & 26 \% & 4 \\ 9 & 8 & 15 & 23 & 47 & 13 \\ 2 & 3 & 8 & 11 & 17 & 16 \\ & & 2 & 1 & 7 & 19 \\ & 1 & & 2 & 3 & 21 \\ & & & & & 13\end{array}$

$100 \% \quad 100 \% \quad 100 \% \quad 100 \% \quad 100 \%$

$\begin{array}{llllll}5 \% & 5 & 5 & 6 & 6 & 100\end{array}$

Females

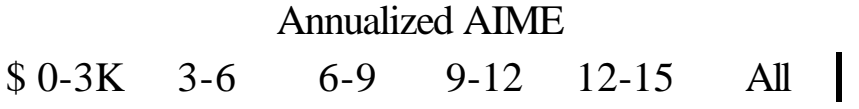

$\begin{array}{rccccc}13 \% & & & & & 7 \% \\ 4 & 21 \% & & & & 5 \\ 5 & 4 & 20 \% & & & 5 \\ 4 & 3 & 4 & 19 \% & & 5 \\ 3 & 3 & 2 & 5 & 18 \% & 4 \\ 11 & 11 & 9 & 8 & 10 & 11 \\ 15 & 13 & 12 & 8 & 10 & 13 \\ 18 & 18 & 16 & 13 & 8 & 15 \\ 16 & 23 & 23 & 23 & 20 & 18 \\ 1 & 5 & 14 & 24 & 36 & 15 \\ & & & & & 2\end{array}$

$100 \% \quad 100 \% \quad 100 \% \quad 100 \% \quad 100 \%$

$\begin{array}{lllll}31 \% & 18 & 14 & 11 & 8\end{array}$

100 
Table 7

Baseline Measures of Distributions of Own Social Security Benefits and Taxes for All Age Eligible Respondents

\begin{tabular}{|c|c|c|c|c|c|c|c|c|c|c|c|}
\hline \multirow[b]{2}{*}{ Annualized AIME Range* } & \multicolumn{11}{|c|}{ Annualized Individual AIME Deciles } \\
\hline & $\$ 0-0.2 \mathrm{~K}$ & $0.2-4$ & $4-7$ & $7-11$ & $11-16$ & $16-21$ & $21-26$ & $26-31$ & $31-38$ & $38+$ & All \\
\hline Average Lifetime Taxes* & $\$ 0 \mathrm{~K}$ & 8 & 21 & 38 & 57 & 79 & 105 & 131 & 156 & 186 & 78 \\
\hline Average Lifetime Benefits* & 0 & 16 & 37 & 48 & 59 & 72 & 86 & 97 & 106 & 113 & 63 \\
\hline \multicolumn{12}{|l|}{ Measures of Redistribution: } \\
\hline Gini Coefficient & - & 0.17 & 0.17 & 0.15 & 0.15 & 0.15 & 0.13 & 0.10 & 0.09 & 0.07 & 0.19 \\
\hline Share of Benefits & - & & & & & & & & & & \\
\hline $\begin{array}{l}\text { Redistributed Within } \\
\text { the Decile }\end{array}$ & & $12.2 \%$ & 12.0 & 10.8 & 11.1 & 10.5 & 9.5 & 6.9 & 5.9 & 4.7 & 14.1 \\
\hline Share of Benefits & - & & & & & & & & & & \\
\hline $\begin{array}{l}\text { Redistributed From } \\
\text { Other Deciles }\end{array}$ & & $57.2 \%$ & 53.0 & 37.0 & 21.6 & 11.3 & 1.4 & -8.9 & -18.9 & -33.0 & - \\
\hline \multicolumn{12}{|l|}{ Share of Total } \\
\hline $\begin{array}{l}\text { Redistribution Coming } \\
\text { to the Decile }\end{array}$ & $-2.3 \%$ & 10.1 & 21.8 & 19.8 & 14.4 & 9.1 & 1.3 & -9.7 & -22.4 & -42.0 & - \\
\hline \multicolumn{12}{|l|}{ Rate of Return Percentiles: } \\
\hline $90 \%$ & & 6.3 & 6.1 & 5.0 & 4.3 & 3.8 & 3.6 & 3.0 & 2.6 & 2.0 & 4.8 \\
\hline $75 \%$ & & 5.3 & 5.3 & 4.5 & 3.8 & 3.4 & 3.1 & 2.5 & 2.1 & 1.7 & 3.9 \\
\hline $50 \%$ & & 4.7 & 4.6 & 3.9 & 3.3 & 2.9 & 2.4 & 2.1 & 1.9 & 1.5 & 2.6 \\
\hline $25 \%$ & & 4.0 & 4.0 & 3.2 & 2.6 & 2.2 & 2.0 & 1.8 & 1.6 & 1.3 & 1.6 \\
\hline $10 \%$ & & 3.3 & 3.1 & 2.4 & 1.7 & 1.5 & 1.6 & 1.6 & 1.4 & 1.1 & 0.4 \\
\hline
\end{tabular}

*In thousands of dollars. 
Table 8

Measures of Redistribution:

Individual vs. Family Benefits and Taxes

$\begin{array}{ccc}\text { Share of Benefits } & \text { Gini } & \text { Median Rates } \\ \text { of Return }\end{array}$

All Respondents

Males

Females

All Respondents

Males

Females

All Respondents

Males

Females
Own Benefits and Taxes

$14 \%$

7

0.19

0.10

0.17

$2.6 \%$

1.9

3.7

Plus Spouse and Survivor Benefits

11

0.15

3.0

8

0.11

2.6

11

0.16

3.7

Family Benefits and Taxes

10

7

0.14

3.1

2.7

8

0.10

3.5 
Table 9

Share of Benefits Redistributed to Group by AIME Decile

(Figures Are the Percentage of Benefits Accruing to the Decile Which Have Been Redistributed from Other Deciles)

\begin{abstract}
Annualized AIME Range*
Own Benefits and Taxes

Including Spouse and Survivor Benefits

Family Benefits and Taxes
\end{abstract}

Annualized AIME Range*

Own Benefits and Taxes

Including Spouse and Survivor Benefits

Family Benefits and Taxes

*In thousands of dollars.

Annualized Individual AIME Deciles

$\begin{array}{cccccccccc}\$ 0-0.2 & 0.2-4 & 4-7 & 7-11 & 11-16 & 16-21 & 21-26 & 26-31 & 31-38 & 38+ \\ - & 57 \% & 53 & 37 & 22 & 11 & 1 & -9 & -19 & -33 \\ - & 51 & 47 & 30 & 14 & 5 & -2 & -6 & -12 & -19 \\ 26 & 23 & 18 & 11 & 3 & -3 & -9 & -12 & -16 & -23\end{array}$

Annualized Family AIME Deciles

$\begin{array}{lccccccccc}\$ 0-3 \mathrm{~K} & 3-8 & 8-14 & 14-20 & 20-26 & 26-31 & 31-36 & 36-42 & 42-49 & 49+ \\ 33 \% & 50 & 28 & 13 & 4 & -4 & -10 & -13 & -15 & -8 \\ 25 & 44 & 22 & 9 & 2 & -1 & -4 & -7 & -10 & -12 \\ 30 & 23 & 13 & 3 & -2 & -2 & -4 & -7 & -10 & -16\end{array}$


Table 10

Share of Benefits Redistributed to Group by Earnings Decile

(Figures Are the Percentage of Benefits Accruing to the Decile Which Have Been Redistributed from Other Deciles)

\begin{tabular}{|c|c|c|c|c|c|c|c|c|c|c|}
\hline & \multicolumn{10}{|c|}{ Individual Significant Annual Earnings Deciles* } \\
\hline & $\$ 0-6 \mathrm{~K}$ & $6-10$ & $10-14$ & $14-17$ & $17-21$ & $21-26$ & $26-31$ & $31-37$ & $37-48$ & $48+$ \\
\hline Own Benefits and Taxes & $53 \%$ & 50 & 38 & 25 & 13 & 3 & -7 & -15 & -21 & -21 \\
\hline Including Spouse and Survivor Benefits & 46 & 43 & 30 & 18 & 7 & 1 & -6 & -11 & -14 & -9 \\
\hline \multirow[t]{3}{*}{ Family Benefits and Taxes } & 28 & 20 & 14 & 6 & 1 & -5 & -11 & -15 & -16 & -14 \\
\hline & \multicolumn{10}{|c|}{ Combined Significant Annual Earnings Deciles* } \\
\hline & $\$ 0-13 K$ & $13-21$ & $21-29$ & $29-35$ & $35-41$ & $41-46$ & $46-53$ & $53-62$ & $62-79$ & $79+$ \\
\hline Own Benefits and Taxes & $43 \%$ & 20 & 2 & -3 & -5 & -5 & -5 & -3 & -4 & -6 \\
\hline Including Spouse and Survivor Benefits & 36 & 14 & 2 & -1 & 0 & -2 & -4 & -4 & -6 & -4 \\
\hline Family Benefits and Taxes & 21 & 7 & 3 & 1 & 2 & -2 & -3 & -4 & -7 & -5 \\
\hline
\end{tabular}

*Significant earnings are indexed yearly earnings that amount to at least 25 percent of the average of the high five years of indexed earnings. 
Figure 1

Social Security Rates of Return by AIME and Annual Earnings Deciles 25th-75th Percentile Ranges, with Medians Indicated

Returns on Individual Benefits and Taxes



Returns on Family Benefits and Taxes

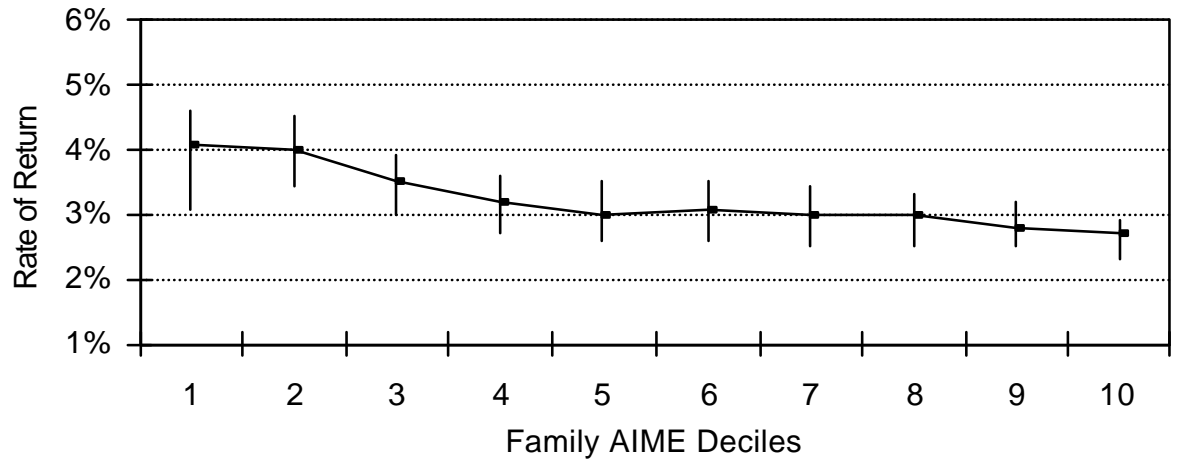

Returns on Family Benefits and Taxes

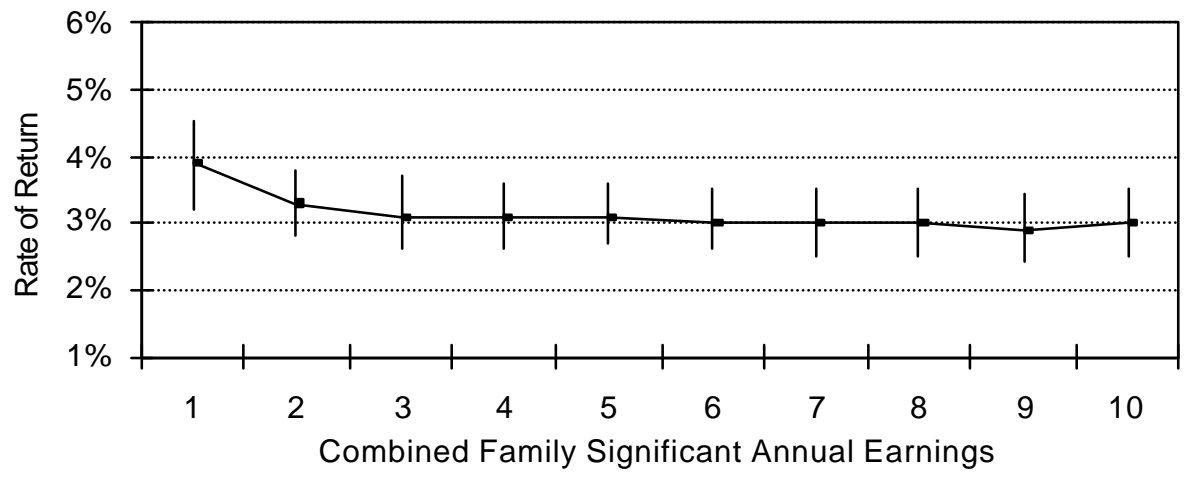

